\title{
Media Industries and Engagement
}

\author{
Annette Hill and Jeanette Steemers ${ }^{1}$ \\ University of Lund and King's College London \\ annette.hill @ kom.lu.se and jeanette.steemers @ kcl.ac.uk
}

\begin{abstract}
:
The aim of this special section is to critically analyse the complex issues at work in understanding the theories, processes and practices of engagement as it relates to media industries. There is a need to open up the notion of engagement as a concept that captures subjective and shifting relations with media. In such a way, this section focuses on media engagement within the industry as multifaceted, working across political and public spheres, policy and industry sectors, audiences and popular culture. Articles debate the meaning of engagement as an object of measurement in policy research, and audience information systems, where ratings data and social media analytics attempt to measure and secure engagement for audiences and consumers of cross media content. Alongside a notion of engagement as quantitative data, there is also a sense of engagement as a subjective and slippery term and articles in this special section also debate the meaning of engagement as signifying personal and collective relations with policy and social issues, or cultural artefacts and events. Thus, policy and industry discourses of engagement as a measurement of interest intersect with, and at times counteract, wider debates about engagement within social media, political activism and popular culture.
\end{abstract}

Keywords: media engagement, policy engagement, audience engagement

\section{Media Engagement}

Engagement refers to the various ways we encounter and experience media within politics, society, and culture. In short, engagement matters, but what we mean by engagement is open to debate. The aim of this special section is to critically analyze the complex issues at work in understanding the theories, processes, and practices of engagement as it relates to media industries. For industry research, engagement is something to capture and measure as a performance indicator. Ratings, social media analytics, and newspaper reviews are the primary ways of measuring audience engagement as a basic definition of interest. And yet engagement is so much more than the public's interest in something, as it captures the subjective positions of other people, such as producers creating content that engages us, professionals promoting and marketing content for mass and niche audiences, and fans, producers, and users experiencing media content. 
This special section in Media Industries makes an intervention into industry discourses of engagement as measurements of interest to open up the notion of engagement as a concept that captures our subjective and shifting relations with media. In such a way, this section focuses on media engagement within the industry as multifaceted, working across political and public spheres, policy and industry sectors, audiences and popular culture. Articles in the special section debate the meaning of engagement as an object of measurement in policy research, and audience information systems, ${ }^{2}$ where ratings data and social media analytics attempt to measure and secure engagement for audiences and consumers of cross media content. Alongside a notion of engagement as quantitative data, there is also a sense of engagement as a subjective and slippery term. Thus, articles in this special section also debate the meaning of engagement as signifying personal and collective relations with policy and social issues, or cultural artifacts and events. We can see how policy and industry discourses of engagement as a measurement of interest intersect with, and at times counteract, wider debates about engagement within social media, political activism, and popular culture.

Research on theorizing media engagement suggests different subjective stages of engagement, interaction, and participation in culture. For example, in Media and Political Engagement, ${ }^{3}$ Peter Dahlgren charts the affective turn in political communication and media, communication, and cultural studies. He argues that both rational and subjective dimensions are crucial to models of civic subjectivity and reflections on normative visions of democracy. John Corner has argued in his book Theorising Media ${ }^{4}$ that there is an increasing interest in subjectivity, and notions of engagement, interaction, and participation in media industry and academic research. According to Corner, engagement refers to engaging with and through the media, suggesting different points of connection and participation with media content. Both scholars highlight an urgent need to define, theorize, and research what is meant by engagement in different contexts. This suggests researchers need to critically reflect on the relationships between media, such as journalism, television, film, and social media, and other factors that help shape the structures and processes of engagement.

Current research on media engagement places much emphasis on political dimensions, for example, passionate politics, or social media engagement and political activism. Zizzi Paparcharissi ${ }^{5}$ explores what she calls the private sphere of democracy in the digital age, where blogs and Twitterspheres contain affective networked publics. As Dahlgren points out in his book The Political Web, ${ }^{6}$ social media engagement is also a powerful element of political participation in conjunction with political action.

Within audience studies, there is quantitative and qualitative research that focuses on different types of interaction, engagement, and disengagement with multiplatform brands, social media, sports, and other live media events. This kind of multimethod and multisite research draws on a tradition of audience studies within popular culture that looks at processes and practices, that is to say the dynamic and often contradictory ways people encounter and experience cultural artifacts. ${ }^{7}$

Within media industries, there is also a policy dimension to engagement where media industry stakeholders often form part of a policy community ${ }^{8}$ who engage in debate to work toward a policy solution on a particular issue, ${ }^{9}$ sometimes collaborating with other stakeholders and interacting with each other to reach a common negotiated position. Under these 
circumstances, the audience or the public are just one stakeholder among many other vested stakeholder interests, particularly from industry, who may have a more strongly articulated and influential position including better and more frequent access to policy-makers in government departments.

The overall aim of the section is to argue for a complex semantics of engagement as a concept that captures different interests, feelings, and involvements - from love, hate to indifference. As situated within the media industries, a semantics of engagement is suggestive of the shifting meanings of the concept within the policy sector, or within creative labor in the television industries, for example, and the changing relationships people forge with media content. Researchers in this special section critically reflect on the relationships between media, such as policy discourses on children's television, the construction of engagement in event television and social media, and other social factors, such as multiculturalism and diversity, that help shape the structures and processes of media industries and cultural engagement.

The special section starts with a dialogue between the television industry and academics, involving industry professionals Jane Roscoe, Head of the London Film School; Douglas Wood, Group Director of Research and Audience Insight at Endemol Shine; Julie Donovan, an entertainment formats consultant; and academic researchers Annette Hill and Jeanette Steemers. The focus of the conversation is the knowledge exchange surrounding industry research on engagement as a measurement of interest and a performance metric for creative values in the television industry, and academic qualitative research on engagement as shifting subjective positions by a fickle audience for television, social media, and pirated content. The race is on to find useful ways of researching engagement that capture both performance metrics and the relationships between people and media content. A case study of the academic and industry collaborative project Media Experiences by Annette Hill, funded by the Wallenberg Foundation at Lund University, highlights the fruitful dialogue about the meaning of engagement in different settings, industrial and everyday life, that can widen our horizon of understanding of this complex term.

This dialogue is followed by an analysis of Policy and Industry Engagement around UK children's television by Jeanette Steemers. This article analyzes recent policy engagement by advocacy (children's media groups; citizens groups) and industry players (broadcasters, industry associations, producers), who have become intensely involved in debates about securing a better financial basis for UK-produced children's television. This engagement in policy runs parallel to a different type of engagement: engagement by child audiences whose consumption of programming, made specifically for them, is changing markedly, and should be influencing the ways in which media policies and strategies around children's content are being formulated by both policy-makers and industry. Domestic children's television is highlighted as both an area of market failure and an area where children's changing consumption practices necessitate different ways of thinking about children's engagement with traditional programming and other applications across a range of platforms, for example, through the British Broadcasting Corporation's (BBC) proposed new iPlay initiative for children. This paper examines the scope and scale of engagement by different players (the BBC, producers, children's advocacy organizations) in the policy process, and how their policy responses to BBC Charter Review were shaped by their own competing political 
concerns rather than perceptions of children's changing engagement and involvement with both children's television and media as a whole. The narrative of policy engagement by industry stakeholders in this instance was highly contested and focused on arguments about access to the licence fee rather than how industry can continue to engage children with public service values and culture.

Research by Annette Hill from the Media Experiences project focuses on engagement as a dialogue between producers and audiences. This article explores the construction of engagement with the reality format Got to Dance, including production and audience research of the live event television for cross-media content. The argument is that there is a spectrum of engagement, from positive to negative to disengagement with the live experience and reality television series. Drawing on quantitative and qualitative audience research, the findings show how audiences switch back and forth between positive and negative modes of engagement and also disengagement. Indeed, for reality television, there is not one type of audience, but rather people switch between different modes of engagement, performing the roles of viewers, consumers, fans, antifans, critics, and participants. Discourses of audience engagement in industry and academic contexts try to label people as one thing or another. But audiences are often performing several roles at the same time, highlighting the multifaceted nature of engagement for varieties of audiences of television and digital content.

The special section ends with Reflections on Engagement by John Corner. In this Afterword, he raises general questions about how the idea of "engagement" relates to the different phases of media production, reception, and use explored in the previous pieces. Drawing on his earlier writing, he notes how different kinds of engagement and involvement occur within a changing "economy of attention" within which commercial activities, media productions, and the politics of media industries have to operate. In this economy, visibility is clearly a pressing requirement, although one that does not by itself guarantee engagement. Production strategies to generate the "right" sorts of engagement with the "right" audiences are required, although given the range of options which consumers have to choose from and the array of factors bearing on choice, these strategies do not always meet with success. Corner considers how engagement with media products often leads to forms of engagement beyond them. Finally, he suggests how lines of inquiry in media research might use the term to develop further their understanding of structure, practice, and process.

${ }^{1}$ Annette Hill is a Professor of Media and Communication at Lund University, Sweden. Her research focuses on audiences and popular culture, with interests in media engagement, everyday life, genres, production studies, and cultures of viewing. She is the author of seven books, and many articles and book chapters in journals and edited collections, which address varieties of engagement with reality television, news and documentary, television drama, entertainment formats, live events and sports entertainment, film violence, and media ethics. Her latest book is Reality TV (Routledge 2015), and her next book is Media Experiences (Routledge 2018). 
Jeanette Steemers is Professor of Culture, Media and Creative Industries in the Department of Culture, Media and Creative Industries at King's College London. A graduate in German and Russian, she completed her PhD in public service broadcasting in West Germany in 1990. Her current research interests include the political economy of children's screen media, the future of public service broadcasting, and transformations in media distribution. Recent publications include Creating Preschool Television; Global Media and National Policies (coedited with T. Flew and P. Iosifidis), European Media in Crisis (coedited with J. Trappel and B. Thomass), and Children's TV and Digital Media in the Arab World (with N. Sakr).

${ }^{2}$ Philip Napoli, Audience Evolution (New York: Columbia University Press, 2011).

${ }^{3}$ Peter Dahlgren, Media and Political Engagement (Cambridge: Cambridge University Press, 2009).

${ }^{4}$ John Corner, Theorising Media (Manchester: Manchester University Press, 2011).

${ }^{5}$ Zizzi Paparcharissi, A Private Sphere: Democracy in a Digital Age (Cambridge: Polity Press, 2010).

${ }^{6}$ Peter Dahlgren, The Political Web (Cambridge: Cambridge University Press, 2014).

${ }^{7}$ Joke Hermes, Re-reading Popular Culture (London: Blackwell, 2005); Annette Hill, Reality TV: Key Ideas. (London: Routledge, 2015).

${ }^{8}$ John W. Kingdon, Agendas, Alternatives and Public Policies, 2nd ed. (Glenview, IL: Longman, 2011).

${ }^{9}$ Hilde van den Bulck and Karen Donders, "Of Discourses, Stakeholders and Advocacy Coalitions in Media Policy," European Journal of Communication 29 (2014): 88-89.

\section{Bibliography}

Corner, John. Theorising Media. Manchester: Manchester University Press, 2011.

Dahlgren, Peter. Media and Political Engagement. Cambridge: Cambridge University Press, 2009.

Dahlgren, Peter. The Political Web. Cambridge: Cambridge University Press, 2014.

Hermes, Joke. Re-reading Popular Culture. London: Blackwell, 2005.

Hill, Annette. Reality TV: Key Ideas. London: Routledge, 2015.

Kingdon, John W. Agendas, Alternatives and Public Policies. 2nd ed. Glenview, IL: Longman, 2011.

Napoli, Philip. Audience Evolution. New York: Columbia University Press, 2010). Papacharissi, Zizzi. A Private Sphere: Democracy in a Digital Age. Cambridge: Polity Press, 2010. van den Bulck, Hilde, and Karen Donders, "Of Discourses, Stakeholders and Advocacy Coalitions in Media Policy." European Journal of Communication 29 (2014): 83-99. 